\title{
El arbitraje internacional de inversión en materia energética del ius imperii al ius gestionis \\ International energy investment arbitration del ius imperii al ius gestionis
}

\author{
Lenin Ramirez Matus ${ }^{1}$ \\ Arturo Enrique Jasso Rodriguez ${ }^{2}$
}

\begin{abstract}
RESUMEN
El presente trabajo es un estudio de carácter cualitativo con diseño no experimental, que tiene como objetivo analizar el arbitraje de inversión en materia energética a nivel internacional con especial referencia a México y otros países latinoamericanos, a partir de la revisión de la literatura se encontró que la reforma energética de 2013 a la constitución y las leyes federales, estableció expresamente mecanismos alternos de solución de controversias como instrumentos para resolver el incumplimiento de contratos en el ámbito de hidrocarburos, de ahí que el arbitraje sea una herramienta donde las partes puedan acudir cuando el estado actúe como un particular en las relaciones que haya contraído con un inversionista, de manera que, al ser este una figura innovadora en el campo energético internacional hace que los países latinoamericanos y los inversionistas la consideren como una nueva solución alterna preferente al sistema de justicia tradicional por vía administrativa.

Palabras clave: arbitraje internacional, contratos, estado, hidrocarburos, inversionista
\end{abstract}

\begin{abstract}
This paper is a qualitative study with a non-experimental design, and the main objective is analyze international energy investment arbitration with special reference to Mexico and other Latin American countries, based on the literature review we founded that the 2013 energy reform to the constitution and federal laws, established alternative mechanisms to solve conflicts as instruments for resolving the breach of contract in the hydrocarbons field, hence arbitration could be a tool where parties involved can go when the state acts as an individual in the relationships that it has contracted with an investor, it is consider as a new preferential alternative solution to the traditional justice system by administrative route.
\end{abstract}

Keywords: International arbitration, contracts, state, hydrocarbons, investor

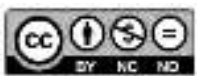

\footnotetext{
${ }^{1}$ Estudiante de la maestría en métodos de solución de conflictos y derechos humanos, Universidad Juárez Autónoma de Tabasco, leninmatus@hotmail.com

${ }^{2}$ Profesor Investigador y Estudiante del doctorado en métodos de solución de conflictos y derechos humanos, Universidad Juárez Autónoma de Tabasco, artjasso753 @ gmail.com
} 


\section{Introducción}

El presente estudio tiene como objetivo analizar uno de los mecanismos alternos de solución de controversias más importantes en el mundo como es el arbitraje, el cual ha existido desde tiempos antiguos para dirimir controversias de distintos tipos. En ese sentido, desde la antigüedad el arbitraje ya era utilizado, tal como Zappala (2010) menciona era el único procedimiento judicial de arreglo, que se reflejaba desde las culturas antiguas hasta el medioevo, incluso hasta la revolución francesa. Posteriormente, Fernández, Sánchez y Ortega señalan (2011) que el arbitraje internacional parte de la práctica anglo-norteamericana que se desarrolló, después de la independencia de Estados Unidos de Norteamérica con el tratado Jay, y ulteriormente tras la guerra de secesión en el célebre arbitraje de Alabama de 1872.

En ese sentido, interesa analizar el mecanismo especial del arbitraje internacional conocido como el arbitraje inversionista internacional, que empezó a utilizarse ampliamente a partir de la firma de tratados como los Bilaterales de Inversión (Bits) en 1958, y cuando el Banco Mundial inició la Convención ICID en 1965, En ese sentido, la doctrina especializada menciona: "El arbitraje de inversión es por ahora elegido como el mecanismo de solución de controversias en miles de tratados y contratos de inversión y conlleva a cientos de casos por años, en la práctica entre Estados y Empresas Extranjeras. (Böckstiegel, 2018, p. 420.)

En ese orden de ideas, en el caso de México, a partir de la reforma energética de 2013, se ha considerado al arbitraje internacional de inversión como un nuevo mecanismo de solución de controversias que resuelve conflictos entre inversionistas extranjeros y órganos del estado mexicano, estos últimos como la Comisión Federal de Electricidad y Petróleos Mexicanos. De igual manera, este tipo de soluciones alternas es utilizado por otros países latinoamericanos con los inversores, de ahí que se considere al arbitraje inversionista energético internacional como una instancia más efectiva que las acciones judiciales previstas en la normatividad nacional de cada país, dada las características especiales que entrañan este tipo de conflictos.

Por ende, el presente documento pretende demostrar como México y los países latinoamericanos han llevado a cabo el ejercicio de esta solución alterna en el ámbito internacional energético, y de qué manera el ius imperii ha sido desplazado paulatinamente por el ius gestionis tanto en la legislación interna de cada país como en la práctica de los inversionistas en materia energética y el Estado a nivel internacional, en razón de la efectividad que el arbitraje les asegura a los contratistas extranjeros. 


\section{La doctrina francesa del ius imperii y el ius gestioniis}

El tema de la inversión energética internacional y la resolución de sus conflictos a través del arbitraje, parte de la doctrina administrativa francesa conocida como el ius imperii y el ius gestionis de ahí que sea necesaria analizar brevemente la teoría que establece cuando el estado actúa como un ente público y cuando como ente privado.

Como García (2008) indica la distinción de lo que conoce como los actos de imperio y los actos de gestión, parten de la costumbre jurídico-romana en el derecho administrativo. En ese sentido, para los romanos los actos del ius imperii quedaban bajo la regulación del derecho administrativo, mientras que los actos de gestión, quedaban bajo el régimen de derecho privado.

Seguidamente, como señala el autor de referencia, la anterior distinción que delimitaba los alcances del derecho administrativo fue cuestionada a finales del siglo XIX, debido a que, los actos que realizaban los órganos del estado también caían en actos de naturaleza tertium genus, que son aquellos de carácter autoritario enmarcados en el derecho administrativo sin ser actos de gestión pública.

Por otra parte, Espugles (2018) menciona que la creciente participación de los particulares en las actividades comerciales internacionales originó un aumento de relaciones con los estados, y consecuentemente, la multiplicación de actores no estatales en el ámbito internacional que actúan con aquellos, de manera que, también incrementó el número de controversias entre los mismos. Por ende, el autor de referencia menciona:

El Estado tiene un papel peculiar puesto que juega como Estado soberano y sujeto internacional, a la vez que como actor crecientemente activo en el comercio internacional. En este último caso, el Estado se equipará con el resto de sujetos participantes, en condiciones de igualdad (espugles, 2018, p.205).

De los anteriores razonamientos doctrinales, se puede deducir que el estado deja de ser un ente público, un órgano cuyos actos de autoridad dejan de tener efectos debido a que empieza a ser sujeto a reglamentaciones de carácter privado, en el presente caso, sus relaciones comerciales originan que se someta bajo la normatividad comercial, de forma que, cuando llevan a cabo negociaciones con inversionistas extranjeros es lógico que sus actos o los puntos de acuerdo que se establezcan se fundamenten en la misma norma comercial que prevé los supuestos que se presenten en las contrataciones de esta naturaleza.

De ahí que el estado, o las personas públicas de jerarquía diversa adscritas a él, suscriban contratos arbitrales dando lugar a la delimitación de estas contrataciones, las cuales no se elabora en función de un servicio público sino en el caso de la naturaleza de la actividad 
contemplada, los modos de gestión de los servicios públicos, el objetivo que se persigue, y el régimen jurídico al que están apegados los actos comerciales (Merino, 2009).

En ese sentido, Merino (2009) menciona:

La actividad pública sometida a las formas del Derecho privado reclama la posibilidad de acudir al arbitraje y someterse a las obligaciones asumidas. Nada parece contradecir el hecho de que el Estado, desprovisto de prerrogativas de poder público, utilice el arbitraje como medio normal de solución de conflictos jurídicos en el ámbito internacional. La renuncia a la inmunidad que representa el arbitraje puede aceptarse sin trabas en las relaciones jurídico.

En efecto, el estado al dejar de lado su poder de autoridad en las relaciones de derecho privado -que en un momento dado puede contraer con un inversionista-, hace posible que los conflictos sean sometidos al arbitraje, el cual es una solución alterna que resuelve de una forma más efectiva las controversias entre las partes. Por ende, los órganos públicos al contraer obligaciones con los inversionistas en el ámbito internacional, se ven sujetos a una serie de cláusulas de entre las cuales se encuentra estipulada este mecanismo, cuyo panel arbitral -que generalmente está compuesto de tres funcionarios- resolverá de conformidad con los tratados internacionales, los principios que rigen este procedimiento, además, establecerá el lugar en donde se llevara a cabo el proceso y valorará si sus desacuerdos son susceptibles de resolverse a través de este medio.

No obstante, para ver cómo se desarrolla esta solución alterna en el ámbito internacional, es interesante analizar lo que ha mencionado la doctrina especializada respecto al arbitraje de carácter inversionista y su especialidad en el campo energético, cuyo auge ha sido sumamente contundente dentro de la solución de disputas entre los extranjeros y los países.

\section{La reforma Energética y el Arbitraje internacional inversionista}

Dentro de la práctica del derecho internacional, se ha venido analizando un mecanismo de solución de controversias especializado que se conoce como el arbitraje inversionista, el cual tiene su punto de partida a partir del Convenio de Washington de 1965, documento que se creó debido a un evento celebrado por varios miembros del banco mundial.

Desde esta afirmación, como señala Esis:

Este convenio, de enorme trascendencia, estableció como método de solución de conflictos entre estados e inversionistas los mecanismos de arbitraje y conciliación. La celebración de este tratado fue la respuesta acertada de los directivos del banco mundial, ante la necesidad de impulsar la circulación transfronteriza de capitales (p.55). 
En ese tenor, como menciona la autora de referencia, la Convención de Washington reconoció el ius standi al inversionista para dirimir su controversia directamente con el estado receptor, ya sea a través del arbitraje de inversión o la conciliación que en él se establecen, no obstante, sin la necesidad de solicitar la intervención de los tribunales internacionales o bien, hacer valer su protección diplomática. el inversor logra una protección autónoma ya que no depende de la voluntad soberana del estado de su nacionalidad para recibir dicha protección y para establecer el quantum del daño sufrido. (rodríguez, 2005, 2018)

Seguidamente, el convenio de Washigton, creo una institución especializada denominada Centro Internacional de Arreglo de Diferencias relativas a Inversiones (CIADI) la cual se formó con la creación del convenio referido, ya que como Fernández (2016) señala es el más utilizado en el ámbito de las inversiones internacionales debido a sus características especiales, en especial referencia a los caracteres de autonomía e independencia respecto de los tribunales nacionales.

Sin embargo, dentro del ámbito del arbitraje inversionista, se encuentran otros tribunales arbitrales que se apegan a las reglas de la CNUDMI y de igual manera, se encargan de resolver diferencias entre los inversionistas y el estado como la Corte de Arbitraje de la Cámara de Comercio Internacional de París, la Corte de Arbitraje Internacional de Londres, el Instituto de Arbitraje de la Cámara de Comercio de Estocolmo y la Corte Permanente de Arbitraje de la Haya. Asimismo, se han creado diversos tratados internacionales como el Tratado Libre de América del Norte y tratados bilaterales de Inversión (Bits por sus siglas en inglés) que regulan estos procedimientos, empero, en el caso de México, se han firmado Acuerdos para la promoción y protección recíproca de las inversiones y los tratados que contienen capítulos de Inversión.

En ese sentido, tal como Fernández señala:

El arbitraje internacional se ha erigido en la solución preferida de los inversores cuando tienen que buscar una solución a su diferencia con el estado receptor de su inversión. Para un inversor es de gran atractivo contar con un mecanismo de solución de controversias que logra decisiones finales mediante un procedimiento rápido, flexible y donde las partes tienen un considerable control sobre el mismo. A ello debe añadirse además que la iniciación de un procedimiento arbitral se facilita enormemente para un inversor debido a las especiales características de la prestación del consentimiento por parte del estado receptor de la inversión (p.49.).

En ese orden de ideas, la competencia del tribunal del arbitral ante el cual se sometará el conflicto dependerá de la manifestación de voluntad por parte del estado receptor, o bien, de lo que estipule su legislación interna o en Acuerdo de Inversión (AIILS de los más de 3000 existentes) que vincula a un estado con el estado del que es nacional el inversionista, consecuentemente, este aceptara el acuerdo de inversión que se suscribió. En esa tesitura, los 
Acuerdos de Inversión son acuerdos bilaterales donde las partes recíprocamente asumen una serie de protección y promoción de las inversiones realizada por los inversionistas de la parte contratante, "asimismo, se incluyen principios de protección que incluye el tratamiento justo y equitativo, la plena protección y seguridad, el principio de no discriminación, la cláusula de la nación más favorecida, la protección del inversor frente a la expropiación” (Fernández, 2016, p. 50)

De igual manera, dentro del ámbito energético se han resuelto disputas entre los inversionistas y los países, ya que en un momento dado, estos pueden presentar un conflicto que necesita resolverse a través de un arbitraje internacional, de ahí que esta sea una nueva rama del derecho internacional público que se denomina Derecho Internacional de la Inversión Energética (International Energy Investment Law), del cual se han creado diversos tratados Internacionales en esta materia, como el tratado de la Carta de Energía, el cual refleja un enfoque regulatorio en las relaciones de Inversión.

En ese sentido, los conflictos energéticos revisten características especiales para someterse al arbitraje, ya que como Talavera y Ferreiros (2015) señalan, la inversión petrolera consta de características especiales y problemáticas contractuales que necesitan de la solución particular ajena a la práctica general comercial, de manera que, los arbitrajes originados a partir de controversias en inversiones petroleras han formado un género en sí mismo, con soluciones ad hoc, que se vinculan a la rama comercial.

Por ende, los conflictos que se originen en el ámbito energético, pueden someterse al arbitraje internacional, en razón de que sus resoluciones no forman parte de las facultades exclusivas del poder judicial, ya que como Marmolejo (2018) señala el estado no actúa en su carácter de autoridad (ius imperii) sino como un particular en una relación contractual de hidrocarburos (ius gestionis), además, la naturaleza del acto reclamado es de carácter mercantil que tiene como objetivo la exploración y extracción del petróleo ó hidrocarburos, práctica que se considera muy riesgosa y que genera perplejidad para el inversionista extranjero, dado que las sumas que se invierten son sumamente multimillonarias sin recibir nada a cambio, asimismo, se pueden aparecer perdidas de riesgos y económicos y financieros en tales actividades, además se utiliza alta tecnología de frágil ingeniería, se pueden generar cambios climáticos, geológicos, ecológicos, de ahí que el inversionista tengan la opción de acudir a los mecanismos alternos de solución de controversias, en especial referencia al arbitraje dado que este herramienta genera claridad en las inversiones.

En efecto, las obligaciones que se contraen en el sector energético son de carácter privado, las cuales al incumplirse se someten ante un panel arbitral especializado en esta materia, de forma que, dentro del arbitraje se resuelven las cláusulas que se incumplieron en el contrato energético, sin embargo, existe la posibilidad de que el conflicto también se someta 
paralelamente a los tribunales nacionales mediante la vía administrativa, como es el caso de juicio de nulidad, o bien a través del juicio de amparo en el caso mexicano.

Por otro lado, a partir de la reforma energética en 2013 en México, es posible llevar a cabo conflictos en el sector energético a través del arbitraje internacional, dado que a causa de este cambio legislativo y constitucional, se modificaron diversos preceptos, principalmente el artículo 27 constitucional, y en cuanto a la legislación federal, se modificaron algunos artículos de la ley de Petróleos Mexicanos, la ley de Comisión Federal de Electricidad, y la ley de Hidrocarburos, los cuales señalan expresamente cuando es susceptible de someter un conflicto por incumplimiento del contrato a través del arbitraje (ius gestioniis), o bien, cuando se puede ejercer el ius imperii, es decir, la rescisión administrativa de un contrato por parte de los órganos que integran el estado.

En ese sentido, a partir de la reforma energética, la ley de petróleos mexicanos ya contempla la posibilidad de someter un conflicto por medio de arbitraje, sin embargo, la ley en sus preceptos hace limitaciones cuando una controversia entra dentro del ámbito privado y en qué momento se encuentra en el derecho administrativo del estado, es decir, cuando se traten de adquisiciones, arrendamientos y servicios y obras que lleve a cabo PEMEX, su artículo 80 dispone lo siguiente:

Artículo 80.- Todos los actos que se desarrollen dentro del procedimiento de contratación que se regula en el presente Capítulo, hasta el momento del fallo, inclusive, serán de naturaleza administrativa. Una vez firmado el contrato, éste y todos los actos o aspectos que deriven del mismo serán de naturaleza privada y se regirán por la legislación mercantil o común aplicable.

En ese orden de ideas, Petróleos Mexicanos hasta antes de la firma de los contratos por obras y servicios, podrá rescindir administrativamente los contratos que se hayan signado con los inversionistas, por ende, hace susceptible que se impugne dicha decisión a través del juicio de nulidad ante los tribunales correspondientes. Sin embargo, cuando se rige por la legislación privada se puede resolver por medio de los mecanismos alternos de solución de controversias como es el caso del arbitraje, ya que como se mencionó en párrafos anteriores el estado actúa como un particular que contrae obligaciones con un inversionista. En ese tenor el artículo 81 de la ley de la materia ya prevé que los conflictos de esta naturaleza se resuelvan a través de las soluciones alternas, si así lo establecieron en los contratos petroleros, no obstante, se podrán resolver de igual manera si así lo consideran las partes en las instancias del Poder Judicial de la Federación.

Cabe resaltar que el artículo 115 de la Ley de Petróleos Mexicanos ya establece expresamente que las partes puedan acudir a los mecanismos alternos de solución de controversias: 
...cuando hayan establecido expresamente cláusulas o compromisos arbitrales en base a la legislación mercantil aplicable y los tratados internacionales de los que México sea parte. De igual manera se podrá aplicar el derecho extranjero si así lo convinieran, si los actos tienen efectos fuera del territorio nacional.

De manera que, la ley de hidrocarburos hace mención expresa del ius imperii del estado, y su situación de particular frente a un inversionista con el que contrajo obligaciones contractuales en el ámbito energético. En esa tesitura, la ley mencionada, prevé expresamente cuando el estado puede representar su investidura de autoridad ante este tipo de relaciones contractuales, es decir, en qué casos puede llevar a cabo la rescisión administrativa de un contracto energético (ius imperii). Por ende, el ejecutivo federal, a través de la Comisión Nacional de Hidrocarburos, rescindirá los contratos administrativos de conformidad con el artículo 20 en los siguientes casos: a) que en el plazo de 180 días el contratista no inicie o suspenda las actividades previstas para el plan de exploración o el desarrollo de la extracción, sin causa justificada ni autorización de la Comisión Nacional de Hidrocarburos; b) que el contratista no cumpla con los requisitos mínimos sin causa justificada; c) cuando el contratista ceda parcial o totalmente la operación o bien, los derechos que se encuentran estipulados en el contrato de exploración y extracción; d) que se presente un accidente grave causado por dolo o culpa del contratista, como el daño a las instalaciones, fatalidad y perdida de producción; e) que el contratista por más de una ocasión de manera dolosa, o bien, injustificada remita en sus informes información falsa, incompleta, o los oculte a las secretarías del poder ejecutivo como la Secretaría de Energía, la Secretaría de Hacienda y Crédito Público, o a la Comisión Nacional de Hidrocarburos; f) que el contratista no ejecute una resolución de un órgano jurisdiccional; g) finalmente, que el contratista no haga algún pago al estado o la entrega de hidrocarburos de acuerdo a lo estipulado en el contratos de extracción y exploración.

Sin embargo, el ius gestionis se hace presente dentro del artículo 21 de la Ley Nacional de Hidrocarburos, donde las partes tanto el estado como el inversionista pueden someter sus conflictos al arbitraje, cuyos contratos de exploración y extracción pueden someterse a los mecanismos alternativos de solución de conflictos de conformidad con el título IV del Código de Comercio y los tratados internacionales de los cuales el estado mexicano sea parte, pero ni la comisión nacional de hidrocarburos ni los contratistas podrán aplicar leyes extranjeras.

Actualmente, el gobierno de México a través de la Comisión Federal de Electricidad ha solicitado una serie de arbitrajes por incumplimiento de las cláusulas arbitrales por siete gasoductos, donde se obligan a las constructoras a sufragar los gastos en casos de retrasos ajenos a la voluntad de estos organismos. De entre los proyectos donde la Comisión Federal de Electricidad solicitó los arbitrajes para anular algunas cláusulas se encuentran los siguientes: a) Proyecto Tuxpan- Tula, Transportadora de Gas Natural de la Huasteca; b) Proyecto Tula Villa-Reyes, Transportadora de Gas Natural de la Huasteca; c) Samalayuca- 
Sásabe, Carso Gasoducto Norte; d) Guaymas- El oro, Gasoducto de Aguaprieta (Ienova); e) La laguna- Aguascalientes; f) Villa de Reyes- Aguascalientes- Guadalajara; g) Sur de TexasTuxpan, Infraestructura Marina del Golfo (TransCanada- IENova), demandas sometidas ante la Corte Internacional de Arbitraje de la Cámara de Comercio Internacional de París y seis demandas preliminares ante la Corte Internacional de Arbitraje de Londres.

Finalmente, estos son algunos ejemplos de una de las innovaciones que ha traído consigo la aprobación de la Reforma Energética a pesar de que el caso Comissa fue un antecedente donde se llevó a cabo el arbitraje internacional entre un inversionista vs el Estado Mexicano, por ende, esta solución alterna ayudará a que la Comisión Federal de Electricidad y Petróleos Mexicanos resuelvan sus diferencias por claúsulas arbitrales que no cumplan con los requerimientos que se pactaron con el inversor, además, hay una mayor equidad en el laudo que resuelva el conflicto por incumplimiento a alguno de los contratos en el ámbito energético.

\section{La experiencia en países latinoamericanos}

En cuanto a la experiencia en Latinoamérica Fernández (2011) señala que, a la mitad del siglo XX, los países latinoamericanos empezaron a considerar el arbitraje como un mecanismo de solución de controversias, por ende, paulatinamente fueron dejando de lado el recelo y rechazo que sentían por ellos. En ese orden de ideas, dichos países han optado por redactar sus cláusulas donde vayan estipuladas las vías para acudir el arbitraje, así, queda establecido de conformidad con los Acuerdos Internacionales de Inversión o bien, los tratados internacionales que hayan signado los países.

En ese tenor, dentro de los casos más emblemáticos en el sector energético por parte de países latinoamericanos que se hayan sometido a un arbitraje internacional se encuentra el caso de Occidental Petroleum Corporation y Occidental Exploration y Production Company c. Ecuador (caso CIADI $n^{\circ}$.ARB/06/11), donde se le impuso al estado receptor una condena pecuniaria cerca de 1800 millones de Dólares.

El caso citado se suscitó debido a que el gobierno ecuatoriano público un decreto de caducidad el 15 de mayo de 2006 a través del cual se determinaba la terminación del contrato de participación entre la empresa nacional de hidrocarburos perteneciente a ecuador y la empresa americana, mismo que se había creado para la exploración y explotación de los recursos petroleros en la región amazónica ecuatoriana, además, se le debían entregar todos los bienes que se habían aportado para la inversión. El gobierno aludido se basó en una sanción administrativa debido a que la compañía estadounidense había transmitido a un 40\% de la participación a otra compañía, con ello se habían quebrantado los compromisos que se habían acordado en el contrato energético. 
En efecto, en el laudo de 12 de octubre de 2012 se había determinado que los inversores no habían cumplido con la autorización de carácter administrativo hacia el gobierno ecuatoriano, no obstante, el estado había tomado una medida desproporcionada en contra de los inversionistas, en virtud de que no había un trato justo y equitativo hacia ellos, además se consideraba un tipo de expropiación.

En ese sentido, lo interesante de este caso es que en las resoluciones se utilizan los principios de las contrataciones entre las partes, como el principio de trato justo equitativo, además la consideración en el exceso de las expropiaciones, como consecuencia, estos criterios hacen que los árbitros se basen en estos principios rectores para resolver el caso aludido.

Por otro lado, en el sector energético latinoamericano también se encuentra el caso de CMS Gas Transmission c. Argentina (caso CIADI $n^{\circ}$.ARB/01/8), donde el panel arbitral condeno al estado argentino a pagar una sumatoria por 133 millones de dólares más intereses porque se violó el principio de trato justo y equitativo en contra de la empresa americana.

En ese sentido, este asunto se originó a partir de la suspensión de la aplicación de la fórmula de ajuste de tarifas de distribución de gas, ya que dicha decisión afectó a la empresa CMS, en razón de que poseía un 30\% de las acciones en la empresa TGN que se había creado en argentina y que había conseguido una licencia para transportar gas. En ese tenor, la justificación de dicha medida por parte del estado argentino se justificó en que se encontraba en un estado de necesidad a partir de la crisis financiera que vivió el país a partir de los años 2000, asimismo, consideró como medida de emergencia la utilización de esta herramienta, ya que este se encuentra como uno de los principios de los acuerdos bilaterales, sin embargo, el tribunal arbitral consideró que la medida había sido totalmente desproporcionada.

Con respecto a la resolución emitida por el Comité, para efectos de saber en que se basó unos de los principios más importantes que se alegan por los inversionistas en el arbitraje internacional como es el principio de trato justo y equitativo se transcribe lo siguiente de los argumentos vertidos por el Comité: "“la estabilidad del entorno jurídico y empresarial es un elemento esencial del trato justo y equitativo." Adicionalmente, sostuvo que este estándar "es inseparable de la estabilidad y la previsibilidad". Según el Tribunal, el marco jurídico existente al tiempo de la inversión no requiere ser congelado, "pues éste siempre puede evolucionar y ser adaptado a los cambios de las circunstancias", pero no puede "eliminarse...por completo cuando se han asumido compromisos específicos en sentido contrario."

Consecuentemente, el tribunal resuelve de conformidad a los principios generales del derecho, es decir, el comité de arbitraje internacional se apego a lo que el tribunal arbitral argentino ya se había fundamentado respecto al trato equitativo, como consecuencia, al llevar 
a cabo el estudio de fondo, solamente se enfocó en lo que el tribunal arbitral consideró en casos anteriores como la teoría de la imprevisión, ya que en efecto no se pueden eliminar los compromisos pero si adecuarlos a las circunstancias económicas del país.

Del mismo modo cuando el gobierno argentino alega que se encuentra en un estado de necesidad, el tribunal internacional de arbitraje mencionó que este argumento se debe basar conforme las normas consuetudinarias en el derecho internacional lo que resultó que el tribunal argentino no construyera motivos suficientes de que es un estado de necesidad, o bien, un estado de emergencia-

Por ende, a partir del estudio de estos casos, se puede concluir que el tribunal arbitral internacional de carácter ad hoc resuelve tanto los intereses de los inversores y el estado, valoración que va dirigida hacia los principios generales del derecho dentro un caso, además su función es más imparcial, debido a su carácter internacional, y resuelve conforme a derecho, ya que su función se basa en resolver de acuerdo a las circunstancias, los principios, y las nociones de derecho internacional.

\section{Metodología}

\section{Método}

El presente trabajo tiene un enfoque de carácter cualitativo, dado que busca encontrar que tanto es el grado de importancia del arbitraje internacional tanto para los países e inversionistas, asimismo, la experiencia que ha tenido México y los países latinoamericanos en el ámbito energético, por ende se pretende demostrar que la justicia tradicional como la vía administrativa que es el medio más común para nulificar recisiones administrativas de contratos de hidrocarburos, es un medio no tan eficaz como el arbitraje internacional, dado que este último resuelve conforme a los principios de equidad y justicia, ya que si se resuelve por la vía tradicional representa una desventaja para los inversionistas, por no ser nacionales de dichos estados.

\section{Diseño}

La presente investigación se basó en un diseño cualitativo no experimental, que fue producto de una exhaustiva revisión bibliográfica respecto a los temas de arbitraje internacional para inversionistas $\mathrm{y}$ estados cuando se presentan conflictos por incumplimiento de contratos en el ámbito energético. Por ende, como señala Sampieri: $E l$ enfoque cualitativo se selecciona cuando el propósito es examinar la forma en que los individuos perciben y experimentan los fenómenos que los rodean, profundizando en sus puntos de vista, interpretaciones y significados. (p.358) De igual manera Sampieri menciona:

El diseño no experimental podría definirse como la investigación que se realiza sin manipular deliberadamente variables. Es decir, se trata de estudios en los que no hacemos variar en forma intencional las variables independientes para ver su efecto sobre otras 
variables. Lo que hacemos en la investigación no experimental es observar fenómenos tal como se dan en su contexto natural, para analizarlos (p.152)

Seguidamente, se extrajeron los cambios hechos por la reforma energética de 2013 a la Constitución Política de los Estados Unidos Mexicanos y demás leyes, que establecen por primera vez de forma expresa, el arbitraje como un mecanismo alterno de solución de controversias, asimismo se reviso bibliografía en base los países latinoamericanos que han resuelto sus controversias en el ámbito energético, además se revisaron algunas notas periodísticas en línea para conocer si actualmente México esta sometido a algún arbitraje internacional.

\section{Instrumentos}

En la presente investigación se consultaron 2 revistas especializadas, 1 nota periodística, y 13 libros especializados en la materia, que arrojaran opiniones, asimismo, el análisis de cómo ha sido el desarrollo del arbitraje inversionista energético en el contexto latinoamericano.

No obstante, se consulto la legislación de federal como la de petróleos mexicanos y la de hidrocarburos, para llevar a cabo el análisis de los preceptos que establecen el arbitraje como un mecanismo de solución de controversias.

\section{Procedimiento}

En una primera etapa se lleva a cabo la revisión bibliográfica del tema de inversión energética y su participación ante los tribunales internacionales de arbitraje, asimismo, se hace una revisión de los conceptos de ius imperii e ius gestionis, de donde parte la teoría de como un órgano actúa con carácter privado y con carácter público, de ahí que cuando sea de carácter privado los conflictos que se originen con un inversionista puedan someterse ante el panel arbitral internacional

Posteriormente, se hace una revisión de los conceptos básicos de arbitraje inversionista y su especialidad en el ámbito de hidrocarburos, para así llegar a la impactante reforma energética de México en 2013 donde se desglosan la legislaciones federales y sus preceptos que regulan el arbitraje como un mecanismo alterno de solución de controversias, asimismo se cita un caso relevante donde la Comisión Federal de electricidad sometió siete arbitrajes ante los tribunales internacionales de Londres y París.

Finalmente se analizan los casos más relevantes en Latinoamérica respecto al arbitraje internacional en materia energética, como es el caso argentino y ecuatoriano. 


\section{Resultados}

De la revisión bibliográfica, notas periodísticas, y revistas especializadas se identificó que el gobierno mexicano a través de Comisión Federal de Electricidad empieza a someter los conflictos a través del arbitraje internacional en lo que respecta al sector energético, asimismo, se ha visto que los casos sometidos ante el arbitraje internacional se resuelvan más conforme a la equidad de trato justo y equitativo.

\section{Tabla 1}

Concentrado de Casos de arbitraje internacional, 2019

\begin{tabular}{|c|c|c|c|}
\hline $\begin{array}{l}\text { Inversionista vs } \\
\text { Estado }\end{array}$ & $\begin{array}{l}\text { Tribunal de } \\
\text { Arbitraje } \\
\text { Internacional }\end{array}$ & Argumento & $\begin{array}{l}\text { Principio } \\
\text { sustentado }\end{array}$ \\
\hline $\begin{array}{l}\text { Occidental } \\
\text { petroleum } \\
\text { Corporation } \\
\text { vs Ecuador }\end{array}$ & CIADI & $\begin{array}{l}\text { Los } \\
\text { inversionistas no } \\
\text { cumplieron con la } \\
\text { autorización } \\
\text { administrativa } \\
\text { para transmitir sus } \\
\text { derechos, pero el } \\
\text { estado no llevó a } \\
\text { cabo un trato justo } \\
\text { equitativo, además } \\
\text { expropio sus } \\
\text { bienes }\end{array}$ & 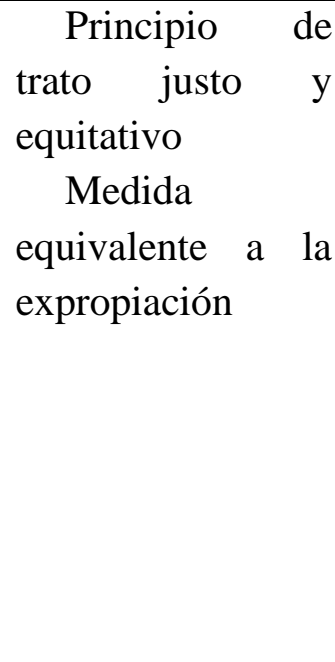 \\
\hline \begin{tabular}{lr}
\multicolumn{1}{c}{ CMS } & Gas \\
Transmission & $\mathrm{c}$. \\
Argentina &
\end{tabular} & CIADI & $\begin{array}{l}\text { A pesar de que } \\
\text { los argumentos no } \\
\text { eran suficientes el } \\
\text { tribunal le } \\
\text { concedió la razón a } \\
\text { CMS Gas } \\
\text { Transmission dado } \\
\text { que las tarifas se } \\
\text { podían adaptar a } \\
\text { las circunstancias } \\
\text { económicas del } \\
\text { país }\end{array}$ & $\begin{array}{l}\text { Principio de } \\
\text { trato justo } \\
\text { equitativo } \\
\text { Estado de } \\
\text { necesidad o Estado } \\
\text { de Emergencia }\end{array}$ \\
\hline
\end{tabular}




\begin{tabular}{clcc}
\hline $\begin{array}{c}\text { Iberdrola } \\
\text { Energía }\end{array}$ & CIADI & El tribunal & Medida de \\
c. Guatemala & arbitral desestimo & expropiación \\
& el argumento & \\
& debido a que la \\
& empresa española \\
& no $\quad$ motivo \\
& suficientemente \\
& los actos de \\
& reducción de tarifa \\
& eléctrica por parte \\
de Guatemala & \\
como una medida \\
de expropiación
\end{tabular}

Por ende, los argumentos en los laudos van enfocados conforme a los principios generales del derecho que se violentan, dependiendo de las circunstancias del caso concreto que se presenten ante los tribunales de arbitraje internacional.

\section{Conclusiones}

Finalmente se concluye que el arbitraje internacional en materia energética es una solución alterna eficaz y es la opción más favorable para los inversionistas debido a que, el panel ad hoc que se constituye para llevar a cabo la solución, adecua sus funciones de manera imparcial, lo que lleva a que analizar de una forma más detalladas las soluciones que ya vienen de los países y se consideren los principios que rigen la justicia alternativa internacional, como es el caso de un principio justo equitativo y una medida de expropiación.

En ese sentido, el principio que comúnmente sustentan los inversores ante los tribunales de arbitraje internacional es el principio relativo al trato justo y equitativo. De ahí que los tribunales arbitrales resuelvan las diferencias en base a las normas consuetudinarias y los principios generales del derecho, y los inversores busquen sus soluciones a través de esta vía alterna voluntariamente.

El arbitraje puede considerarse como un triunfo del reconocimiento de la autonomía de la voluntad, en la medida en que son los particulares quienes eligen el lugar donde se resolverá la controversia, el o los árbitros encargados de la decisión, la ley que será aplicada y el alcance de las decisiones que puede adoptar el tribunal. (Madalena y Montoya, 2018, p.75)

Sin embargo, a partir de la reforma energética en México, las diferencias que se susciten después de la firma del contrato de hidrocarburos es posible someterlos ante los tribunales 
arbitrales internacionales, como es el caso de Comisión Federal de Electricidad donde se mencionó los litigios que tiene ante el arbitraje internacional de Londres y París. Por ende, la nulidad administrativa pasa a ser la última opción que los inversionistas pretendan ejercer, no obstante, en caso de escoger la vía de solución alternativa es necesario plasmarlo dentro de las cláusulas arbitrales.

Por ende, el estado deja a un lado su ius imperii para someterse a un nuevo mecanismo de solución de controversias como el arbitraje, donde el ius gestionis se encuentra presente para la solución de conflictos ante el arbitraje internacional.

\section{Referencias}

Castillo, T (2008) El contrato de estudio internacional, México: UNAM, Instituto de Investigaciones jurídicas.

Esis Villarroel Ivette, S. (2018) La expropiación en el sistema internacional de Protección de Inversiones extranjeras, Valencia: Tirant lo Blanch.

Fernández T., A. F., Sánchez A., y Ortega J.M, (2011) Lecciones de Derecho Internacional Público, Valencia: Tirant lo Blanch.

Fernández E. (2016) El arbitraje Internacional como mecanismo de protección de las inversiones energéticas en Latinoamérica. El caso de las inversiones provenientes de la república popular china, en Espluges C. (ed.) Inversiones extrajeras en el sector energético en Latinoamérica, (pp.47-73) Ciudad de México: Tirant lo blanch.

Böckstiegel H.K, (2018) Arbitraje Comercial y de Inversión: ¿cuán diferentes son hoy? En Flores Senties (ed.) Retos Contemporáneos del Arbitraje Internacional, Ciudad de México: Tirant lo Blanch.

Espluges C. (2018), Arbitraje y derecho administrativo. Teoría y realidad, Valencia: Tirant lo blanch.

Madalena I, y Montoya N. Función y Deberes del árbitro, En Flores Senties (ed.) Retos Contemporáneos del Arbitraje Internacional, Ciudad de México: Tirant lo Blanch.

Merino J.F. (2009) Curso de derecho arbitral, Valencia: Tirant lo Blanch.

Marmolejo M.A. (2018), La no arbitrabilidad de la rescisión administrativa en los nuevos contratos de Hidrocarburos, Ciudad de México: Tirant lo Blanch.

H. Roberto (2014) Metodología de la Investigación, Sexta Edición México: McGraw-Hill

Talavera C. A. y Ferreyros, M. (2015). Alcances preliminares para la aplicación de la Lex Petrolea en el Perú. Forseti. Revista de Derecho, (1) Lima. Recuperado de http://forseti.pe/

Zapalla F. (2010, julio-diciembre) Universalismo Histórico del Arbitraje, Vniversitas. Bogotá (Colombia) (121): Recuperado de www. Redalyc.org.

García Rodríguez, I., (2005) Pluralismo jurídico e inversión extranjera: Las controversias entre el inversor y el estado receptor, en Pacis A, Obra Homenaje al profesor Julio D. 
González Campo. Derecho Internacional Privado, Derecho Constitucional y Varia. (pp.1563-1592) Eurolex y Universidad Autónoma de Madrid, Madrid. 